\title{
Study on Vibration Characteristics of Wind Turbine Rotor Blades Based on ANSYS
}

\author{
Lei Lu' ${ }^{1,}$, Lida Zhang ${ }^{2, b}$ \\ ${ }^{1}$ Yingxiuwan Hydropower General Factory of State Grid Sichuan Electric Power Company, \\ Dujiangyan, Sichuan, 611830, China \\ ${ }^{2}$ Xihua University, Chengdu, Sichuan, 610039, China \\ aabclulei2009@163.com, bzlida@126.com
}

Keywords: Wind turbine, Rotor blades, Finite element, Vibration frequency.

Abstract. For rotor blades of the $1.5 \mathrm{MW}$ wind turbine, combined with ANSYS software, finite element analysis had been made. Vibration frequency on the wind turbine blades at different bands has been calculated. The result provided theoretical basis for the operation of wind turbine.

\section{Introduction}

Wind energy is the kinetic energy generated by the flow of air. It is an inexhaustible renewable energy source without any pollution[1]. The wind speed is changing all the time. The records show that within $0.25 \mathrm{~s}$, the wind speed can be changed from $27 \mathrm{~m} / \mathrm{s}$ to $37 \mathrm{~m} / \mathrm{s}$. These gusts provide varying pneumatic loads for wind turbines. The wind speed changes not only in size, but also in direction. With changes in the wind direction, the wind turbine shaft moves toward the wind and generates a gyro torque, which acts on the blade as a variable inertia load. In addition, for large wind turbines, the weight of the blade itself is a non-negligible load, and this load is also constantly changing for the rotating blades. Under the joint action of these factors, the wind turbine is prone to chatter during the operation, resulting in damage to the blades. Therefore, the finite element analysis of the rotor blades to study the natural frequency and mode shape of the blades, so as to predict and analyze the structural dynamic characteristics under the action of the external load, it is very necessary.

\section{Wind wheel blade model overview}

This paper takes the wind turbine blade of DF82 wind turbine as an example to calculate the object. Its three-dimensional model is shown in Fig. 1 . The rated power is $1.5 \mathrm{MW}$. It is generally installed in inland areas. The design service life is 20 years. The rotation direction is clockwise. The parameters are shown in Table 1.

According to the literature[2], the extreme thrust load on the unit swept surface of the wind wheel is taken as (1-1).

$$
t_{r o t}=300 \mathrm{~N} / \mathrm{m}^{2}
$$

The total thrust load acting on the rotor is (1-2).

$$
T_{\text {rot }}=t_{\text {rot }} A_{\text {rot }}=300 \mathrm{~N} / \mathrm{m}^{2} \times 5358.98 \mathrm{~m}^{2}=1607694 \mathrm{~N}
$$

This load is shared by the three blades and is distributed linearly in a triangular pattern (Figure 2). The minimum is $0 \mathrm{~N} / \mathrm{m}^{2}$ at the root end, and the maximum is $30.042 \mathrm{~N} / \mathrm{m}^{2}$ at the tip. The extreme load that each blade should bear is (1-3)、(1-4).

$$
\begin{aligned}
& \mathrm{T}_{\text {blade }}=\frac{\mathrm{T}_{\text {rot }}}{\mathrm{B}}=\frac{1607694 N}{3}=535.9 \mathrm{kN} \\
& \mathrm{M}_{\text {rot }}=\frac{2}{3} \times 40.25 \mathrm{~m} \times 535.9 \mathrm{kN}=14379.98 \mathrm{kN} \cdot \mathrm{m}
\end{aligned}
$$


Among them,

$\mathrm{T}_{\text {rot }}$ - Total thrust load acting on the rotor,

$t_{\text {rot }}$ - Extreme thrust load on unit swept surface,

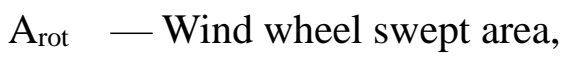

Tblade - Thrust load acting on a single blade,

B - The number of blades of the wind wheel,

$\mathrm{M}_{\mathrm{rot}}$ - Torque generated by thrust load on a single blade.

Table 1 Related parameters of blade section

\begin{tabular}{|c|c|}
\hline Item & Parameter \\
\hline wind wheel diameter $/ \mathrm{m}$ & 82.624 \\
\hline blade length $/ \mathrm{m}$ & 40.25 \\
\hline number of leaves & 3 \\
\hline wind wheel swept area $/ \mathrm{m}^{2}$ & 5358.98 \\
\hline wind level & 17.3 \\
\hline rated speed $/\left(\mathrm{r} \cdot \mathrm{min}{ }^{-1}\right)$ & 10.8 \\
\hline rated wind speed $/\left(\mathrm{m} \cdot \mathrm{s}^{-1}\right)$ & 5 \\
\hline wind wheel inclination $/(\mathrm{degree})$ & 0.489 \\
\hline maximum power factor $\left(\mathrm{C}_{\mathrm{pmax}}\right)$ & $3($ average value of 10 minutes $)$ \\
\hline entering wind speed $/\left(\mathrm{m} \cdot \mathrm{s}^{-1}\right)$ & 25 (average value of 10 minutes $)$ \\
\hline cutting out wind speed $/\left(\mathrm{m} \cdot \mathrm{s}^{-1}\right)$ & 30 (gust of 3 seconds $)$ \\
\hline cutting out wind speed $/\left(\mathrm{m} \cdot \mathrm{s}^{-1}\right)$ & \\
\hline
\end{tabular}

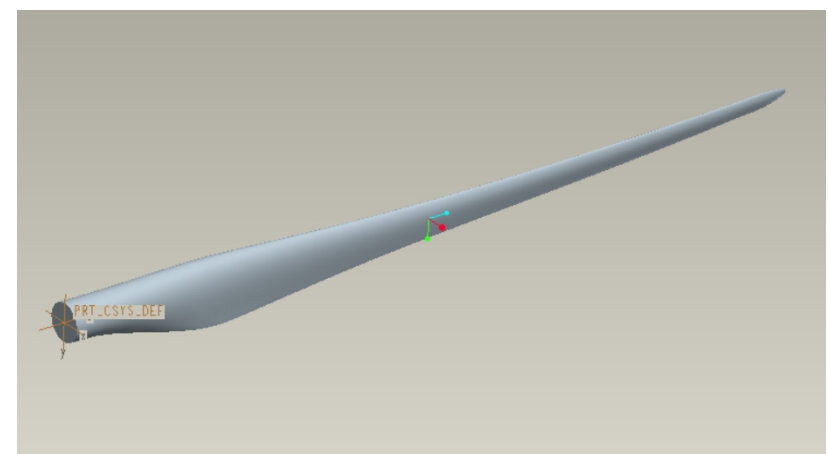

Fig.1 Three-dimensional solid model of wind turbine blade

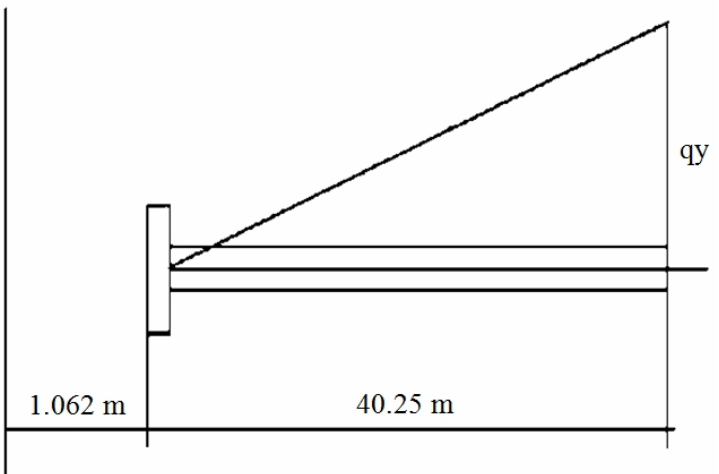

Fig. 2 Load distribution on the blade

\section{Dynamic analysis of blades}

The three-dimensional model of the blade was saved as a ".x_t" file, imported into the ICEM CFD for meshing, and then the modal analysis of the blade was performed on the ANSYS platform. The material of the blade is glass fiber reinforced composite (GRP). The material performance parameters are shown in Table 2.

Finally, ANSYS calculation results were obtained. Reading the results of ANSYS general-purpose processor, the various frequencies and various vibration modes of the wind turbine blades from first-order mode to eleventh-order mode were obtained, as shown in Fig. 3(a-k).

When the blades are stationary $(0 \mathrm{~m} / \mathrm{s})$, the natural frequencies from first-order mode to eleventh-order mode are shown in Table 3. 


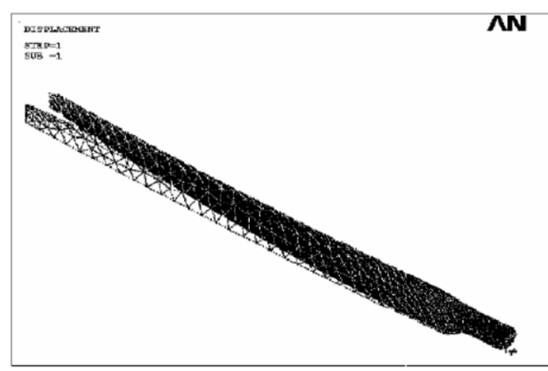

(a) First-order mode

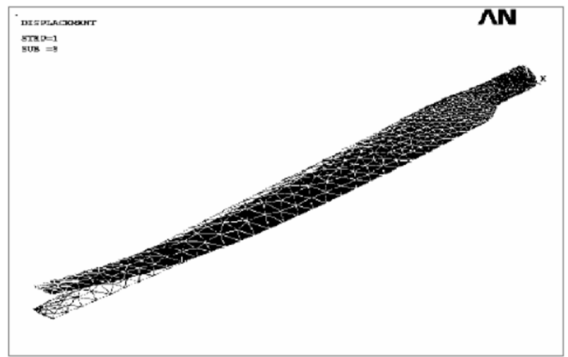

(c) Third-order mode

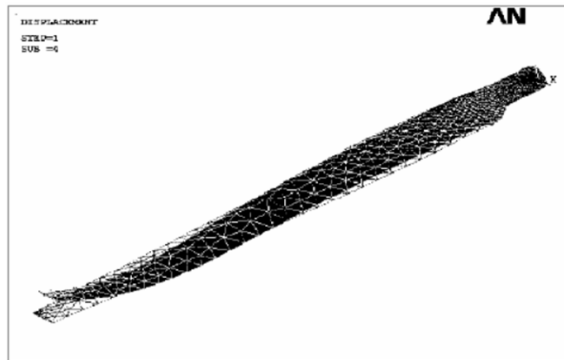

(e) Fifth-order mode

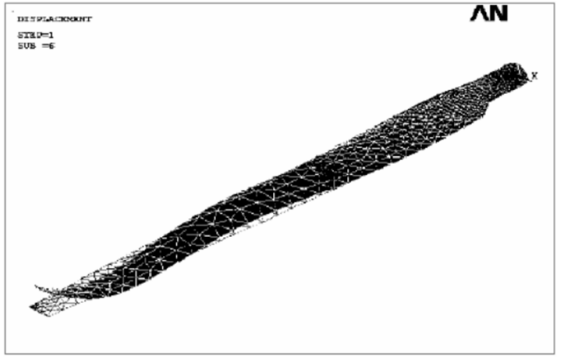

(g) Seventh-order mode

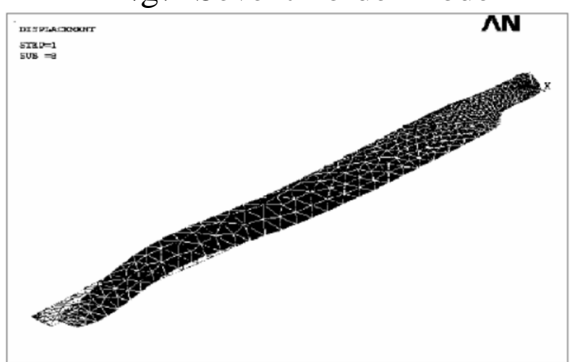

(i) Ninth-order mode

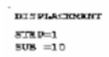

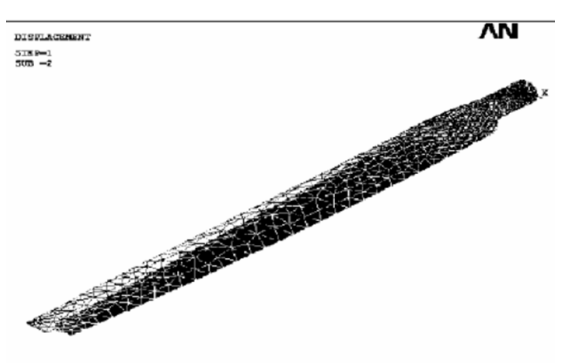

(b) Second-order mode

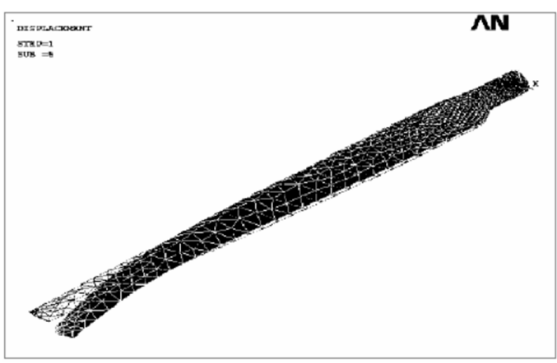

(d) Fourth-order mode

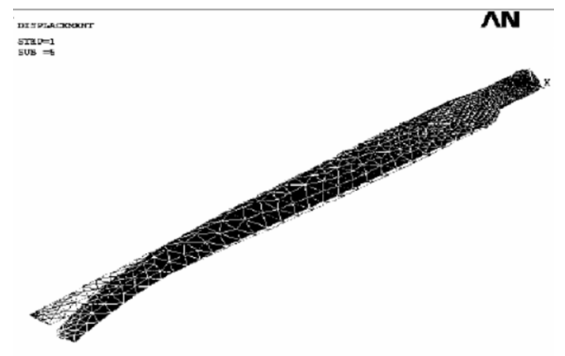

(f) Sixth-order mode

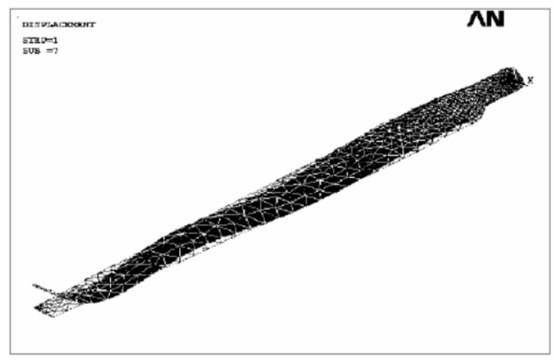

(h) Eighth-order mode

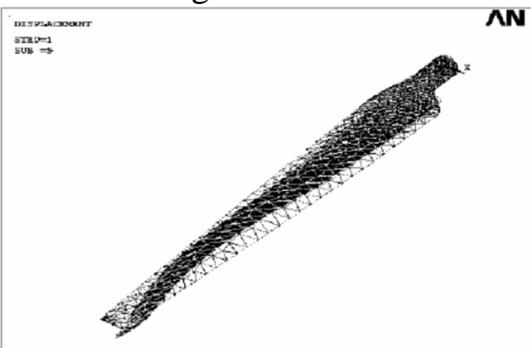

(j) Tenth-order mode AN

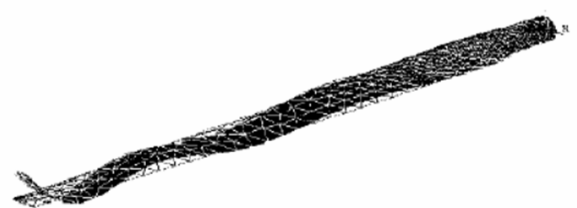

(k) Eleventh-order mode

Fig.3 Vibration mode of blade modes 
Table 2 Material performance parameters

\begin{tabular}{|c|c|c|c|c|c|}
\hline Materials & $\begin{array}{l}\text { Spreading } \\
\text { modulus/E }\end{array}$ & $\begin{array}{c}\text { Radial } \\
\text { modulus/E } \mathbf{E}_{2}\end{array}$ & $\begin{array}{c}\text { Shear } \\
\text { Modulus/G }\end{array}$ & $\begin{array}{l}\text { Poisson's } \\
\text { ratio / }\end{array}$ & Density/ $\rho$ \\
\hline GRP & $25.5 \mathrm{GPa}$ & $11.8 \mathrm{GPa}$ & $2.84 \mathrm{GPa}$ & 0.2 & $\begin{array}{l}1.7 \times 10^{-6} \\
\mathrm{~kg} / \mathrm{mm}^{3}\end{array}$ \\
\hline
\end{tabular}

Table 3 Natural frequencies at rest of blade

\begin{tabular}{|c|c|c|c|c|c|c|c|c|c|c|c|}
\hline Order & 1 & 2 & 3 & 4 & 5 & 6 & 7 & 8 & 9 & 10 & 11 \\
\hline $\begin{array}{c}\text { Frequency } \\
/ \mathbf{H z}\end{array}$ & 0.774 & 4.329 & 9.727 & 14.892 & 21.914 & 29.407 & 39.905 & 52.358 & 61.266 & 72.594 & 83.217 \\
\hline
\end{tabular}

It can be seen from the figure, about vibration modes of the blade, from first-order mode to sixth-order mode, the first form is mainly the flapping vibration, and the second form is mainly the shimmy. The first few steps are dominated by waving and oscillating vibrations and their mutual coupling vibrations, that is, flapping and oscillating vibrations are the main vibrations of wind turbines. Seventh-order waving and torsional vibration until the eleventh-order vibration mode can clearly see the effect of torsional vibration.

(1) From the calculation results, it can be seen that the frequency of flapping vibration and oscillating vibration of the wind turbine blade is low, and the frequency of torsional vibration is high.

(2) Calculations show that in the vibration of wind turbine blades, the coupled vibrations of flapping and pendulum vibrations will play a major role and the effects of torsional vibrations will be less.

(3) Because the root portion of the wind turbine blade is not completely equivalent to the fixed support, the calculated frequency value may be higher than the actual value.

(4) In the resonance analysis and response calculation of conventional mechanical vibration, the natural oscillation frequency of the blade is a very important parameter. In actual operation, the rotation of the blade will change its natural frequency; and the natural frequency of the blade during flutter is the frequency of the coupled vibration of the system. But under normal circumstances, the system's coupling vibration frequency is close to the free vibration frequency of a single blade in the static state. Therefore, it is considered that the free vibration frequency of a single blade is the natural vibration frequency during its operation.

(5) In this paper, the first-order frequency calculated of the $1.5 \mathrm{MW}$ wind turbine blade is close to the test frequency of $0.78 \mathrm{~Hz}$ with an error of $-0.77 \%$, which shows that the wind turbine blade modal analysis method adopted in this paper is feasible.

\section{Conclusions}

In this paper, ANSYS software is used to perform modal analysis on the wind turbine blades, the frequencies and vibration modes of the wind turbine blades from first to eleventh order are obtained. The first-order frequency of the wind turbine blade is close to its natural frequency, so the first-order frequency is considered to be the natural frequency of the wind turbine blade. The analysis results basically meet the data of $1.5 \mathrm{MW}$ wind turbines. Therefore, when the wind turbine is in operation, the rotation frequency of the rotor blades should be avoided from the integral multiple of the natural frequency of the blades to avoid resonance.

\section{Acknowledgements}

This work was financially supported by the Sichuan Science and Technology Support Plan Project (Project No. 2014GZ0084: 1. Research on Blade Vibration Mechanism of Large Horizontal Axis Wind Turbine; 2. Research on Aerodynamic Shape Optimization Design of Wind Turbine Blades). 


\section{References}

[1] Junfeng Li. 2008 China Wind Power Development Report [M]. Beijing: Environmental Science Press, 2008. (In Chinese)

[2] Jensen PH. Static Test of Wind Turbine Blades[J]. Test station for wind mills, Risoe National Laboratory, 1986.

[3] Gasch R, Twele J. Wind Power Plants: Fundamentals,Design, Construction and Operation [M]. 2002.

[4] Huping Liu. Wind turbine blade design and chatter analysis [D]. Xi'an: Northwestern Polytechnical University, 2005. (In Chinese)

[5] Benli Li, Xiangeng Song, Dexing He, et al. Wind turbine structural dynamics[M]. Beijing: Beihang University Press, 1999. (In Chinese)

[6] Lachun Ren, Lida Zhang. Study on Parametric Modeling Method of Wind Turbine Blade Based on UG [J]. Mechanical design and manufacturing, 2008, (6). (In Chinese)

[7] Weiping Xin. Dynamic Characteristics and Response Analysis of Rotating Blades of Wind Turbines [D]. Shantou: Shantou University, 2005. (In Chinese)

[8] Lachun Ren. Wind turbine blade structure design and analysis [D]. Chengdu: Xihua University, 2008. (In Chinese)

[9] Rongsheng Chen. Research on Structural Dynamic Characteristics of Wind Turbine[D]. Chengdu: Xihua University, 2009. (In Chinese) 